\title{
Reformas estructurales de México en el sexenio de Felipe Calderón: la energética
}

\author{
Structural reforms in Mexico during the administration of \\ Felipe Calderon: the energy one
}

\section{Roberto Gutiérrez R.}

Departamento de

Economía UAM-Iztapalapa

<robertogtz@yahoo.com>

Journal of Economic Literature (JEL):

$\mathrm{H}, \mathrm{L71}, \mathrm{Q} 41$

Palabras clave:

Economía del sector público

Hidrocarburos

Energía (demanda y oferta)

Keywords:

Public Economics

Hydrocarbon fuels

Energy (Demand and Supply)

\section{Resumen}

La falta de instrumentación de la reforma energética aprobada por el Congreso mexicano en noviembre de 2008 ejemplifica bien los intereses de la administración calderonista en materia de reformas estructurales: se pusieron en práctica una serie de ajustes de carácter burocrático-administrativo incapaces de permitir a la industria petrolera revertir la caída que se inició después de que el campo Cantarell alcanzó su tope de producción, a fines de 2004. Frente a esa emergencia, se mantuvieron muy elevadas las exportaciones de crudo al tiempo que no se instrumentó el mandato de la reforma energética: reducción de las importaciones de productos petroliferos y gas natural, edificación de la refinería Bicentenario, pleno desarrollo del proyecto Aceite Terciario del Golfo, incorporación de los recursos del mar profundo al rango de reservas probadas, dotación a Pemex de autonomía de gestión y financiera, puesta en circulación de Bonos Ciudadanos, impulso a las capacidades tecnológicas de la industria, y desarrollo de energías renovables. La consecuencia evidente es el desgaste de las reformas estructurales de carácter sectorial, lo que hace progresivamente más difícil su discusión e instrumentación futuras.

\section{Abstract}

The lack of implementation of the energy reform approved by the Mexican Congress in November 2008 exemplifies well the achievements of the Calderon administration as for structural reforms is concerned: a number of bureaucratic administrative actions were implemented proving unable to allow the oil industry to reverse the decline that began after the Cantarell field reached its peak production in late 2004. On the face of this emergency, the government kept very high levels of crude oil exports and did not implement the mandate of the energy reform: reduction of imports of refined products and natural gas, edification of the Bicentenario refinery, development of the Aceite Terciario del Golfo project, transformation of resources from the so-called deep sea to the range of proved reserves, financial and management autonomy for Pemex, issue of Citizens Bonds, busting of technological capabilities, and support to the develop of renewable energy resources. The obvious consequence is the erosion of sectoral structural reforms, making it progressively more difficult their debate and future implementation. 


\section{Introducción}

Al inicio del tercer año de la administración de Felipe Calderón (2007-2012) existía la impresión, lo mismo entre los especialistas financieros que entre los inversionistas internacionales, de que la reforma energética aprobada por el Congreso en noviembre de 2008 había sido una muestra de coordinación en dos ámbitos: al interior del poder Ejecutivo, y entre los poderes Ejecutivo y Legislativo. ${ }^{1}$ Asimismo, se esparcía la idea de que Petróleos Mexicanos (Pemex) había dado un paso considerable hacia su autonomía de gestión y financiera. Paralelamente a esta visión, se hizo evidente que, a medida que se fueran poniendo en práctica los cambios legislativos, no se resolverían los problemas que aquejaban a la industria petrolera, por lo menos desde los años noventa del siglo XX, y hacia cuya resolución se había dirigido la reforma. Por el contrario, a partir de 2009 se empezaron a infringir a México una serie de costos sobre los que tanto el Ejecutivo como el Senado de la República, generador el primero de la propuesta y revisor y redactor final de ella el segundo, no previnieron a la sociedad.

Tales costos, enmarcados en las ambigüedades y el lenguaje críptico del sistema político mexicano, son lo suficientemente preocupantes como para acrecentar la duda que ya tenía el país respecto al verdadero beneficio que pueden darle las reformas estructurales, no porque en sí mismas sean vacuas, pues las experiencias de otros países demuestran su enorme utilidad en materia de atracción de inversión extranjera, promoción del comercio exterior, industrialización y por tanto impulso al crecimiento económico y a la generación de empleos formales, ${ }^{2}$ sino porque la administración pública de México no ha mostrado capacidad para hacer que se materialicen en progreso tangible y que los recursos que por una parte se requieren para su instrumentación y por otra se generan cuando entran en operación se transparenten y distribuyan equitativamente. Por el contrario, una y otra vez se han magnificado sus beneficios y se han tenido que justificar sus magros resultados.

El escepticismo se gestó a lo largo de los últimos 15 años del siglo pasado, cuando debido a la crisis del petróleo y la deuda externa se llevó a cabo la primera generación de reformas, todas de tipo macroeconómico: estabilización, finanzas públicas, privatización

1 Los siete decretos de esa reforma (Diario Oficial de la Federación -DOF-, 28 de noviembre de 2008) son: i) Reforma y adiciones al artículo 33 de la Ley Orgánica de la Administración Pública Federal; ii) Reforma y adición a diversas disposiciones de la Ley Reglamentaria del Artículo 27 Constitucional en el Ramo de Petróleo; iii) Reforma, adición y derogación de diversas disposiciones de la Ley de la Comisión Reguladora de Energía; iv) Ley de la Comisión Nacional de Hidrocarburos (nueva); v) Ley para el Aprovechamiento sustentable de la Energía (nueva); vi) Ley para el Aprovechamiento de Energías Renovables y Financiamiento de la Transición Energética (nueva); y vii) Reforma a la Ley Orgánica de Pemex y Empresas Subsidiarias. El paquete incluyó algunos ajustes funcionales a éstas y otras leyes: Reglamento de la Ley de Pemex (4 de septiembre de 2009), adiciones al Artículo $3^{\circ}$ de la Ley Federal de Entidades Paraestatales y al artículo $1^{\circ}$ de la Ley de Obras Públicas y Servicios Relacionados con las mismas, y un párrafo tercero al artículo $1^{\circ}$ de la Ley de Adquisiciones, Arrendamientos y Servicios del Sector Público. Asimismo, previo a la publicación de los decretos se hicieron cambios de gran significación a la Ley Federal de Responsabilidad Hacendaria y a la Ley Federal de Derechos, en materia de Hidrocarburos.

2 Por ejemplo, el modelo de crecimiento con orientación hacia el exterior, mismo que adoptó México a principios de los años ochenta, había servido 15 años antes para impulsar el desarrollo de los Nuevos Países en Proceso de Industrialización, o NICS, por sus siglas en inglés: Corea del Sur, Singapur Taiwán y Hong Kong. 
de empresas paraestatales, eliminación de subsidios, liberalización comercial, desregulación financiera, individualización de cuentas de seguridad social. Esta puesta en operación del modelo de orientación hacia el exterior se justificó en virtud de que, a partir de tales transformaciones, el crecimiento económico de México sería alto y sostenido, la economía se volvería más competitiva, se generarían más empleos y se reducirían la desigualdad y la pobreza (Puyana y Romero, 2009).

Aunque el gobierno de Vicente Fox (2001-2006) no logró poner en práctica ninguna nueva reforma, el de Calderón consolidó cinco en el terreno económico, no todas trascendentales: la fiscal (2007), la del sistema público de pensiones (2007), la energética (2008), la de competencia (2010) y la laboral (2012). . Empero quedó claro, al final de su administración, cuando se cumplían 30 años de aplicación del modelo de orientación hacia el exterior, y luego de que México llegó a convertirse, a principios del siglo XXI, en la nación que más acuerdos comerciales tenía firmados con otros países, que el crecimiento económico de largo plazo había bajado a menos de la mitad del que experimentó durante el "milagro mexicano más 11" (1940-1981). ${ }^{4}$

Dado que este problema era manifiesto desde 2007, pero se acrecentó a partir de la crisis financiera internacional de 2008-2009 (Gutiérrez, 2013), la administración Calderón propuso una nueva generación de reformas económicas, a las que ordenó en cinco áreas: fiscal, energética, laboral, regulatoria y de telecomunicaciones (Calderón, 2009). Su propuesta evidenció la existencia de tres dudas generalizadas por parte de la sociedad

${ }^{3}$ La reforma fiscal tuvo resultados imperceptibles para la recaudación tributaria y grandes problemas de aplicación, debido a que su instrumento principal, el Impuesto Empresarial a Tasa Única (IETU), no fue capaz de hacer que creciera el coeficiente de recaudación, que sigue siendo uno de los más bajos del mundo: entre $10 \%$ y $11 \%$ del producto interno bruto (PIB), sin incluir los gravámenes a Pemex. La energética tuvo el inconveniente de que, tanto el Ejecutivo como el Director General de Pemex se mostraron inconformes porque al pasar por el Legislativo se distanció de su propuesta original, que pretendía mayores facilidades a la inversión privada en las áreas de exploración, explotación, refinación y distribución, y más autonomía de gestión a Pemex (Gutiérrez 2010). La reforma al sistema de pensiones, que se había iniciado en 1997 con la negociación de una nueva Ley del Instituto Mexicano del Seguro Social (IMSS), institución que cubre a los trabajadores asalariados del sector privado, culminó en 2007 con la nueva ley del Instituto de Seguridad y Servicios Sociales de los Trabajadores al servicio del Estado (ISSSTE), que cubre a los trabajadores asalariados del sector público. Estas medidas se potenciarían con la creación del Sistema Nacional de Pensiones, propuesto en el Plan Nacional de Desarrollo 2007-2012 (Presidencia, 2007), y con la consolidación de una especie de aseguramiento en materia de salud para los no asalariados, que es apenas una parte de la seguridad social, mediante la afiliación al Seguro Popular de aquellas personas no inscritas al IMSS y al ISSSTE. La reforma a la Ley Federal de Competencia Económica se llevó a cabo con el fin de asegurar que México transitara de un Estado indiferente ante el poder de los monopolios y oligopolios a otro que ofreciera mayores oportunidades a las pequeñas compañías productoras de bienes y servicios mediante el juego equitativo de las fuerzas del mercado, sin incluir los monopolios estatales, como establece el artículo 28 constitucional. Finalmente, la laboral consistió en la modificación de múltiples artículos de la Ley Federal del Trabajo (LFT) con objeto de abatir el costo de la mano de obra, aumentar la empleabilidad de jóvenes a costa de los trabajadores maduros, despenalizar la flexibilización funcional y numérica, reducir el peso de los sindicatos en las decisiones colectivas y desincentivar el expediente de las huelgas.

${ }^{4}$ El término se acuña a partir de Hansen (1974) quien ubica entre 1940 y 1970 el "milagro mexicano", periodo al que se agregan los 11 años siguientes que, aunque se conocen como "populistas" (Bazdresch y Levy, 1992) lograron mantener el ritmo de crecimiento de la economía arriba de $6 \%$ promedio anual. 
mexicana, independientemente de los intereses de los partidos políticos: en caso de que el Congreso las aprobara ¿estaría dispuesto el Ejecutivo a acatarlas o le parecerían insuficientes, como sucedió con la energética de 2008? ¿Condicionaría su aplicación a que fueran suficientemente liberales y con ello pudieran incidir-de acuerdo con la posición doctrinaria de él y su partido- en el crecimiento económico y el empleo? Y ¿̇aseguraría que los recursos involucrados volvieran a tener orientación productiva? Por ejemplo, durante la época del milagro mexicano, mientras la mayoría de países de América Latina invertía en armamento y fuerzas militares, el sector público de México invirtió en infraestructura, potenciando su crecimiento y situando al país en una posición promisoria (Hansen, 1974).

En este contexto, el presente trabajo pretende mostrar, a partir de la experiencia de la reforma energética de 2008, que el concepto de reformas estructurales se desgastó en el imaginario colectivo debido a su ausencia de resultados palpables. Concretamente, se mostrará que las únicas áreas de la reforma energética que se han puesto en práctica son de carácter burocrático -administrativa (incluso se iniciaron meses antes de la aparición de los decretos de noviembre de 2008), incluyendo la licitación de algunos pozos maduros a partir de la aplicación de una nueva forma de vinculación con la iniciativa privada, los Contratos Integrales de Exploración y Producción (CIEP) y la firma de un convenio con Estados Unidos (EU) para explotar hidrocarburos en yacimientos transfronterizos. Mientras tanto, los aspectos medulares se quedaron esperando su materialización. Por supuesto, la consecuencia directa del énfasis en lo burocrático-administrativo es que se contrató más burocracia de alto nivel y aumentaron el gasto público y la deuda de Pemex, sin que ello se tradujera en incrementos en la capacidad de la entidad para elevar sus reservas probadas, su producción, su productividad, su capacidad de procesamiento y distribución de hidrocarburos, y su potencial tecnológico.

\section{Efectos de la reforma en la industria y el país}

Los únicos puntos en que el gobierno de Calderón instrumentó la reforma energética son los que se presentan a continuación. Todos tienen carácter burocrático-administrativo, excepto el referido al inicio de la licitación de pozos maduros, cuyos efectos tangibles no alcanzaron a palparse en dicha administración.

\section{Aumento del poder regulatorio de la SENER \\ y expansión de la burocracia energética}

Los decretos asociados al cambio de organización del sector energético confirieron al Ejecutivo Federal, a través de la SENER, un enorme poder frente a otras dependencias de la administración pública, Pemex incluido, en las áreas de prospección, exploración y explotación de yacimientos petroleros, así como en las de administración de la industria petrolera y de distribución de productos petroliferos. Esto en virtud de las nuevas funciones que adquirió la SENER al crearse un número importante de órganos en los que el Ejecutivo tiene gran influencia, ya sea por la mecánica de designación de los funcionarios o porque dichos órganos dependen directamente de la SENER. Además, se generó la obligación legal de producir un mayor número de documentos oficiales, tanto en materia de planeación energética como de otros asuntos que se enlistan a continuación. 
A partir de los siete decretos, los organismos creados o reforzados fueron:

- Consejo Nacional de Energía: abocado a la planeación energética de mediano y largo plazos, a proponer a la SENER criterios y elementos de política energética, y a apoyarla en el diseño de la planeación energética a mediano y largo plazos, lo cual quedaría plasmado en un nuevo documento de planeación energética, la Estrategia Nacional de Energía, que se explica adelante.

- Comisión Nacional de Hidrocarburos y su Foro Consultivo: destinados a evaluar y delimitar los recursos petroleros del país, regular y supervisar la exploración y explotación de hidrocarburos, y maximizar la vida útil de los yacimientos.

- Comisión Nacional para el Uso Eficiente de la Energía, antes Comisión Nacional para el Ahorro de Energía, y su Consejo Consultivo: cuyo fin fue promover la eficiencia energética y fungir como órgano de carácter técnico en materia de aprovechamiento sustentable de la energía.

- Consejo Consultivo para el Fomento de las Energías Renovables: integrado por representantes de los sectores industrial, comercial, académico, gubernamental y de la banca de desarrollo, fungiendo como órgano de consulta en la identificación de proyectos y el diseño y desarrollo de programas relacionados con el aprovechamiento de las energías renovables.

- Consejo Consultivo para el Aprovechamiento Sustentable de la Energía: cuyas principales funciones fueron: revisar el programa y el proyecto de trabajo de la Comisión Nacional para el Uso Eficiente de la Energía; elaborar un informe sobre el cumplimiento de las metas y objetivos de ambos documentos; aprobar la creación de grupos de trabajo para la atención de temas específicos; proponer mecanismos para la planeación, desarrollo y ejecución de los programas de eficiencia energética, y promover la participación del sector privado en la aplicación de los programas en materia de aprovechamiento sustentable de la energía.

Los documentos que se generaron a partir de los decretos, y que servirían para justificar el reforzamiento de los grupos de trabajo de la SENER y sus órganos desconcentrados, fueron los siguientes:

- Estrategia Nacional de Energía: a partir de tres ejes rectores -seguridad energética, eficiencia económica y productiva, y sustentabilidad ambiental- se propuso: restituir reservas, revertir la declinación en la producción de crudo y mantener la producción de gas natural; diversificar las fuentes de energía incrementando la participación de tecnologías limpias; incrementar los niveles de eficiencia en el consumo de energía; reducir el impacto ambiental del sector energético; operar de forma eficiente, confiable y segura la infraestructura energética; ejecutar oportunamente las inversiones necesarias en materia de procesamiento; fortalecer la red de transporte, almacenamiento y distribución de gas y petrolíferos; proveer con energéticos de calidad y a precios competitivos a los centros de población marginados, y promover el desarrollo tecnológico y de capital humano para el sector energético. Su horizonte se estableció en 15 años, con revisiones cada 12 meses (la SENER lo propone al Congreso en febrero de cada año). 
- Estrategia Nacional para la Transición Energética y el Aprovechamiento Sustentable de la Energía: mediante este mecanismo se buscó impulsar políticas, programas, acciones y proyectos para una mayor utilización y aprovechamiento de las energías renovables y las tecnologías limpias, promover la eficiencia y la sustentabilidad energéticas y reducir la dependencia de los hidrocarburos.

- Programa Nacional para el Aprovechamiento Sustentable de la Energía: su objetivo fue identificar oportunidades para lograr el aprovechamiento óptimo de la energía y generar ahorros sustanciales para el país en el mediano y largo plazos a partir de los usos finales de la energía. Esto sin inmiscuirse en las estrategias de aprovechamiento sustentable en la transformación y recirculación de energéticos, que representan casi $40 \%$ del consumo de energía del país, y que serían abordadas por la Estrategia Nacional de Energía.

- Programa Especial para el Aprovechamiento de Energías Renovables: abocado a ofrecer opciones energéticas ante el eventual agotamiento de los hidrocarburos. Se centraría en la eficiencia energética y las energías renovables; incorporaba el principio de sustentabilidad energética y se proponía especificar políticas públicas para promover el uso y utilización óptima de fuentes renovables de energía.

- Subsistema Nacional de Información sobre el Aprovechamiento de la Energía: orientado a proponer, registrar, organizar, actualizar y difundir la información sobre los usos finales de la energía por sector, subsector y región geográfica; definir los factores que determinan este comportamiento; llevar un registro sobre los indicadores de eficiencia energética que describen la relación en los usos finales de energía y los factores que los impulsan, y contar con indicadores de eficiencia energética de otros países, con fines comparativos.

Los órganos del sector energético que se crearon o reforzaron con los decretos fueron:

- La Comisión Reguladora de Energía (CRE): órgano desconcentrado de la SENER, la cual reafirmaba su poder regulatorio sobre diversas actividades energéticas asociadas a la venta de primera mano de gas, combustóleo y petroquímicos básicos, así como de los productos que se obtuvieran de la refinación del petróleo y de los petroquímicos básicos. También se incluyeron las actividades realizadas por medio de ductos, los sistemas de almacenamiento que se vinculan directamente a los de transporte o distribución por ducto y los que forman parte integral de las terminales de importación o distribución de dichos productos.

- El Consejo de Administración de Pemex: reforzado con cuatro consejeros profesionales, con lo que el número total de consejeros pasó de 11 a 15.

- La instauración de consejos de administración en cada uno de los cuatro organismos subsidiarios de Pemex: Exploración y Producción (PEP), Refinación (PR), Petroquímica (PP), y Gas y Petroquímica Básica (PGPB). ${ }^{5}$

- La creación de siete comités de Pemex: Auditoría y Evaluación del Desempeño; Estrategia e Inversiones; Medio Ambiente y Desarrollo Sustentable; Transparen-

5 Desde el inicio de su gestión, la administración de Peña Nieto (2013-2018) propuso la eliminación de estos Consejos y la desaparición de las cuatro subsidiarias de Pemex, dejando la toma de decisiones de la entidad en dos direcciones generales. 
cia y Rendición de Cuentas; Desarrollo e Investigación Tecnológica; Remuneraciones; y Adquisiciones, Arrendamientos, Servicios y Obras.

Dentro de la ampliación de funciones a SENER, la reforma previó dos:

- Capacidad de regulación sobre prácticamente todas las actividades que involucraba la reforma energética, desde la planeación hasta la ejecución, bien de manera directa o bien a través de sus órganos desconcentrados, y poder para imponer sanciones a todas las empresas del sector, lo mismo públicas -Pemex entre ellas- que privadas.

- Prelación sobre otras secretarías de Estado, organismos públicos, entidades y municipios de la República en relación con la definición de acciones de exploración y explotación de hidrocarburos. Esto, combinado con el énfasis en que la industria petrolera es de jurisdicción federal, conducia a que las eventuales decisiones de la secretaría en materia de exploración, explotación, refinación, distribución de hidrocarburos y otras se ubicaran por encima de la opinión, los intereses y prioridades económicos y políticos de los gobiernos estatales y municipales; las preocupaciones ecológicas de la Secretaría de Medio Ambiente y Recursos Naturales (SEMARNAT); las restricciones sobre tenencia de la tierra de la entonces Secretaría de la Reforma Agraria (SRA); los conflictos sobre la producción agropecuaria de la Secretaría de Agricultura, Ganadería, Desarrollo Rural, Pesca y Alimentación (SAGARPA), y los eventuales conflictos en materia de asentamientos humanos a cargo entonces de la Secretaria de Desarrollo Social (SEDESOL) y hoy de la Secretaría de Desarrollo Agrario, Territorial y Urbano (SEDATU).

\section{Se agregaron elementos de divergencia al interior del sector}

La creación de nuevos organismos sectoriales y el reforzamiento de los existentes, particularmente alrededor de la SENER, condujo a puntos de vista contradictorios al interior del sector energético e incluso al interior de Pemex:

- En el marco de las funciones de los cuatro consejeros profesionales de Pemex, y presuntamente atendiendo a posiciones partidistas, en dos de éstos surgieron hasta 2012 fuertes críticas a diversos aspectos de la política de extracción de hidrocarburos de Pemex. Destacó al respecto el ritmo de explotación y el método de recuperación secundaria del yacimiento Cantarell: inyección de nitrógeno en vez de vapor de agua, como propusieron en su momento algunos expertos y se hizo evidente en el foro de discusión sobre la reforma convocado por el Senado a mediados de $2008 .{ }^{6} \mathrm{~A}$ ello se podría atribuir tanto su declinación desde 2211 miles de barriles diarios (MBD) en diciembre de 2003 hasta 396 MBD en diciembre

${ }^{6}$ En el yacimiento más productivo al finalizar el sexenio, Ku-Maloob-Zaap (K-M-Z), se aplicaba el mismo método de recuperación (inyección de nitrógeno) que en Cantarell, inyectándole unos 650 millones de pies cúbicos diarios de dicho gas, cantidad que duplicaba la del gas natural que producía. 
de 2012, lo que implicó un descenso de 1815 MBD, equivalente a -82\% (Pemex, 2004 y CNH, 2013) como el hecho de que el factor de recuperación final (cantidad de hidrocarburos que se logre extraer del yacimiento), no rebasará $50 \%$. Otra crítica, a tratar más adelante, es el apego al régimen constitucional de los contratos a terceros.

- Por su parte, recién creada, la CNH (2010) hizo tres críticas concretas a Pemex. En primer lugar, la presunción de inviabilidad económica del proyecto Aceite Terciario del Golfo (ATG), que entre 2007 y 2012 absorbió inversiones promedio de 30000 millones de pesos anuales, y cuya producción pico, alcanzada en diciembre de 2012, fue de apenas 75 MBD, 2.9\% del total nacional, a pesar del trabajo de seis empresas privadas en la zona (Ica Flour, Sclumberger Inc., Watherford International LTD, Halliburton Corporation, Baker Hughes Inc. y Tecpetrol), beneficiarias de una gran parte de los recursos mencionados. En segundo lugar, las desviaciones detectadas entre las cifras de venteo y quema de gas programadas vis a vis las observadas en los pozos productores de petróleo de Cantarell, en virtud de que Pemex determinó, a principios del gobierno de Calderón, que ese sería el costo inevitable de mantener la producción de crudo del yacimiento en niveles razonables de recuperación de la inversión, dada su fase de franca declinación. ${ }^{7} Y$ en tercer lugar, la recalificación de las reservas de petróleo crudo del país: de acuerdo con Pemex las totales (probadas, probables y posibles) al primero de enero de 2010 eran de 278994 MMB, de las que sólo se habían extraído $36849 \mathrm{MMB}$, es decir 13.2\%, distribuidas territorialmente de acuerdo a lo mostrado en las barras color intermedio de la gráfica 1. A mediados de 2010 una revisión de la CNH (2010) basada en cifras de la propia entidad (Pemex, 2010a) las subió a 304458 MMB, de las que se habían extraído apenas 12\%, con la siguiente distribución geográfica: 69802 MMB en la zona Marina Noreste; 26492 MMB en la zona Marina Suroeste; 166660 MMB en la Norte, y 41498 MB en la Sur, como muestran las barras oscuras de la misma gráfica. Debe notarse que los mayores aumentos se ubican en las zonas marinas.

7 El mismo Director General de Pemex entre 2006 y 2009, Jesús Reyes-Heroles González-Garza, se refirió con posterioridad al problema manifestando que las dos opciones que se tenían respecto a Cantarell eran: quemar grandes cantidades de gas a la atmósfera para mantener activo el proyecto o cerrar los pozos. Dado lo costoso de la segunda opción, se optó por la primera. 


\section{Gráfica 1}

Reservas totales de petróleo crudo hasta el 1 de enero de 2010 según

Pemex y la $\mathrm{CNH}, \mathrm{y}$ producción acumulada. -Millones de millones de barriles-

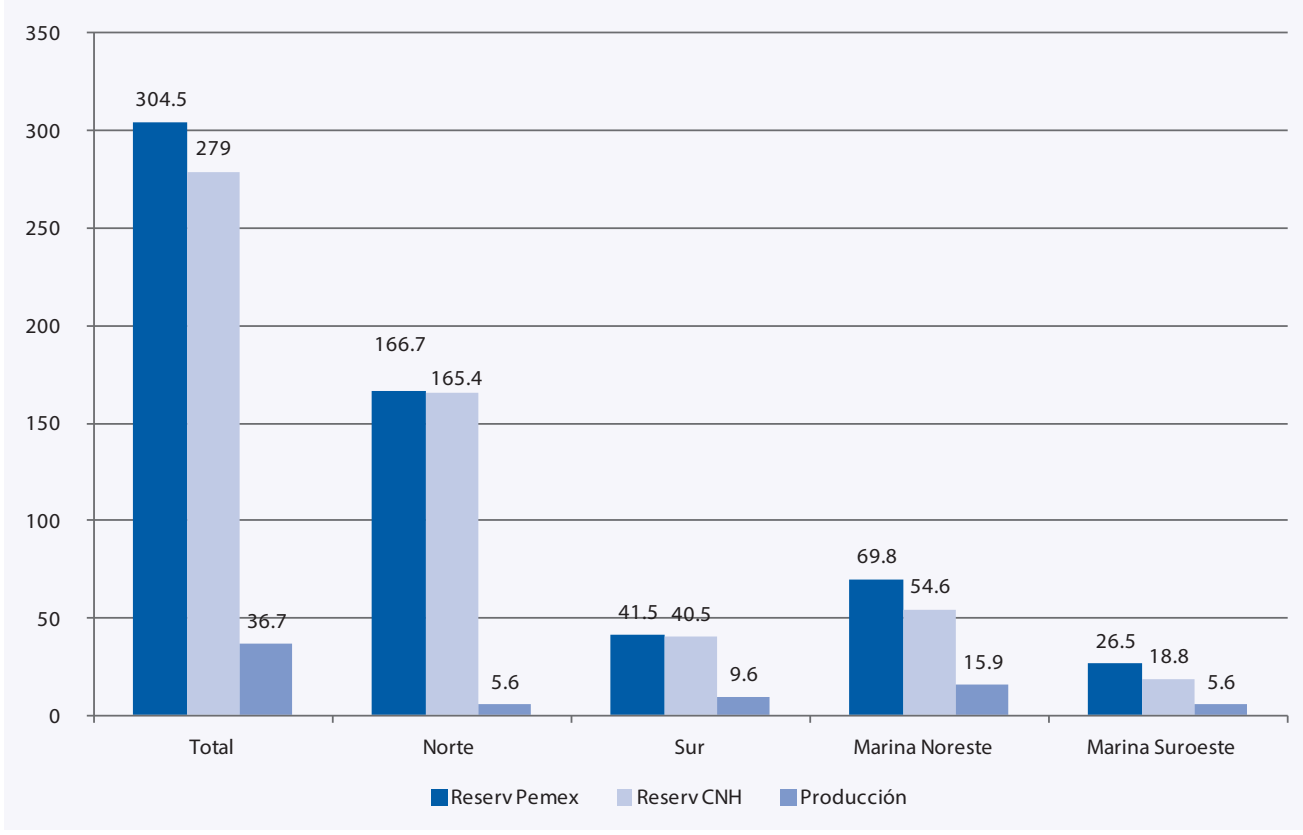

Fuente: CNH (2010) y Pemex (2010a).

- Como también se observa en la gráfica 1, la zona donde la CNH reconoce que existe el mayor volumen de reservas (60\% del total) es en la Norte, que incluye el proyecto ATG, mismo con el que, como se mostró, la CNH es más escéptica.

- Las cifras anteriores no incluyen las eventuales reservas en las aguas profundas de la parte mexicana del Golfo de México, pues al final de la administración calderonista seguían sin determinarse y los expertos nacionales e internacionales no parecían tan optimistas, aún reconociendo que en el lado estadounidense de dicho golfo el bombeo asciende a más de un millón de barriles diarios (MMBD).

Se registró una aguda elevación de la nómina del sector público y Pemex

- Los decretos previeron la creación del Fondo para la Transición Energética y el Aprovechamiento Sustentable de la Energía, mismo para el que, en el Presupuesto de Egresos de la Federación (PEF) para el Ejercicio Fiscal 2009 se dispuso destinar tres mil millones de pesos. Asimismo, se aclaró que, antes del 30 de junio de 2009, la Secretaría de Hacienda y Crédito Público (SHCP) consolidaría la información sobre las provisiones de recursos del sector público incluidas en el PEF 2009, a fin de establecer el monto mínimo de recursos a programarse para los ejercicios fiscales subsecuentes. Para 2010 y 2011, decía el decreto, el monto presupuestado sería de tres mil millones de pesos, el cual se actualizaría por la variación esperada del Índice Nacional de Precios al Consumidor (INPC) de 2009 al año presupuestado. 
- Asimismo, la mayor parte de los decretos incluyeron un artículo transitorio que establecía: "La Cámara de Diputados proveerá lo necesario en el Presupuesto de Egresos de la Federación para que la Secretaría de Energía cuente con los recursos humanos y materiales para dar cabal cumplimiento a las atribuciones conferidas con motivo del presente Decreto". Esto a pesar de que los servicios personales del sector público absorbían (y lo siguen haciendo) cerca de $70 \%$ de los ingresos tributarios del gobierno federal, lo que quiere decir que el monto de recursos disponible para inversión es muy bajo; además, los sueldos de la alta burocracia de México son de los más altos del mundo, como muestra el cuadro 1 para el caso de las remuneraciones, en términos reales, de los presidentes, secretarios, subsecretarios y directores generales en 13 países desarrollados y en desarrollo.

- Hay que aclarar que los cálculos sólo se refieren a remuneraciones anuales; es decir, no incluyen algunas percepciones extraordinarias dentro de las que destaca una prima de riesgo para los funcionarios que trabajan en dependencias involucradas con el Consejo de Seguridad y que en una discusión de fines del 2010, a propósito de la formulación del PEF 2011, el subsecretario de Egresos de la SHCP reconoció ascendía a 813 mil 427 pesos corrientes. Asimismo, estableció que las remuneraciones totales del Ejecutivo para 2011 serían de 4 millones 140 mil 963 pesos, a precios de 2010, es decir casi 4 millones 300 mil pesos corrientes (SHCP, 2010a). La cifra equivale a 358333 dólares al tipo de cambio prevaleciente en ese momento, casi el doble de lo que reporta la gráfica 2 para 2002 (186,100 dólares). Esto implica remuneraciones mensuales de 358 mil 333 pesos, cerca de 30 mil dólares al tipo de cambio prevaleciente.

\begin{tabular}{|c|c|c|c|c|}
\hline \multicolumn{5}{|c|}{$\begin{array}{l}\text { Cuadro } 1 \\
\text { Comparación internacional de remuneraciones anuales reales de altos funcionarios } \\
\text { del gobierno federal (Dólares de 2002) }\end{array}$} \\
\hline & Presidente & Secretario & Subsecretario & Director Gral. \\
\hline Estados Unidos & 243600 & 107500 & 96700 & 89100 \\
\hline México* & 186100 & 179200 & 171800 & 123100 \\
\hline Reino Unido & 167300 & 124900 & 94400 & 86400 \\
\hline Alemania & n.d. & 144500 & 81700 & 64800 \\
\hline Promedio & 108867 & 85382 & 72760 & 59270 \\
\hline Francia & n.d. & 74700 & 74700 & 74700 \\
\hline Italia & n.d. & 84500 & 79000 & n.d. \\
\hline España** & 77000 & 67900 & 61800 & 54100 \\
\hline Argentina ${ }^{\star \star \star}$ & 36000 & n.d. & n.d. & n.d. \\
\hline Brasil & 41000 & 38700 & 29600 & 25900 \\
\hline Chile & 29400 & 28900 & 28400 & 26800 \\
\hline Filipinas & 98600 & 12800 & 9500 & 5400 \\
\hline Perú & 100800 & 75600 & n.d. & 42400 \\
\hline
\end{tabular}


Los sueldos netos integran el conjunto de pagos monetarios (sueldo integrados, compensaciones, bonos) de los funcionarios.

n.d. No disponible, algunas veces porque no se pudo obtener a tiempo.

*En México, los datos de los subsecretarios y de los directores generales son los promedios simples proporcionados por la Subsecretaría de Egresos de la SHCP.

**Los datos para España se presentan en términos brutos, ya que el cálculo del impuesto sobre la renta resultó impracticable.

***Para efectos comparativos el tipo de cambio de Argentina corresponde al previo a su crisis devaluatoria de principios del siglo. Según decreto 172/2002 dichos funcionarios no podrán ganar más que el presidente (US\$36 $000 \mathrm{al}$ año), aunque no se cuenta con información exacta sobre sus percepciones. Fuente: Carrillo y Guerrero (2004).

Gráfica 2

Plazas ocupadas en Pemex

-Miles-

- Por lo que se refiere a la nómina de Pemex, además de que sus plazas son muy costosas, el número de éstas ha crecido mucho en los últimos años: en 2000, antes de iniciar la administración Fox, el total era de 132.7 miles de personas; al cerrar ésta e iniciar la de Calderón, en 2006, se ubicó en 141,3 miles, y al cerrar 2012 llegó a 150.7 miles, como muestra la gráfica 2. Es decir que en la administración Fox el número aumentó 8.6 miles ( 1.4 miles promedio anual), en tanto que en la de Calderón subió 9.4 miles ( 1.6 miles promedio anual). Sumando las dos administraciones el aumento fue de 18 mil plazas, número que representa un incremento de $13.6 \%$ respecto a 2000. Por áreas, los principales aumentos se dieron en PEP (cerca de 10 mil), Pemex Corporativo (cerca de 7 mil) y Servicios Médicos (más de 1.5 miles). Esto se amortiguó con ligeras disminuciones en PR y PP.

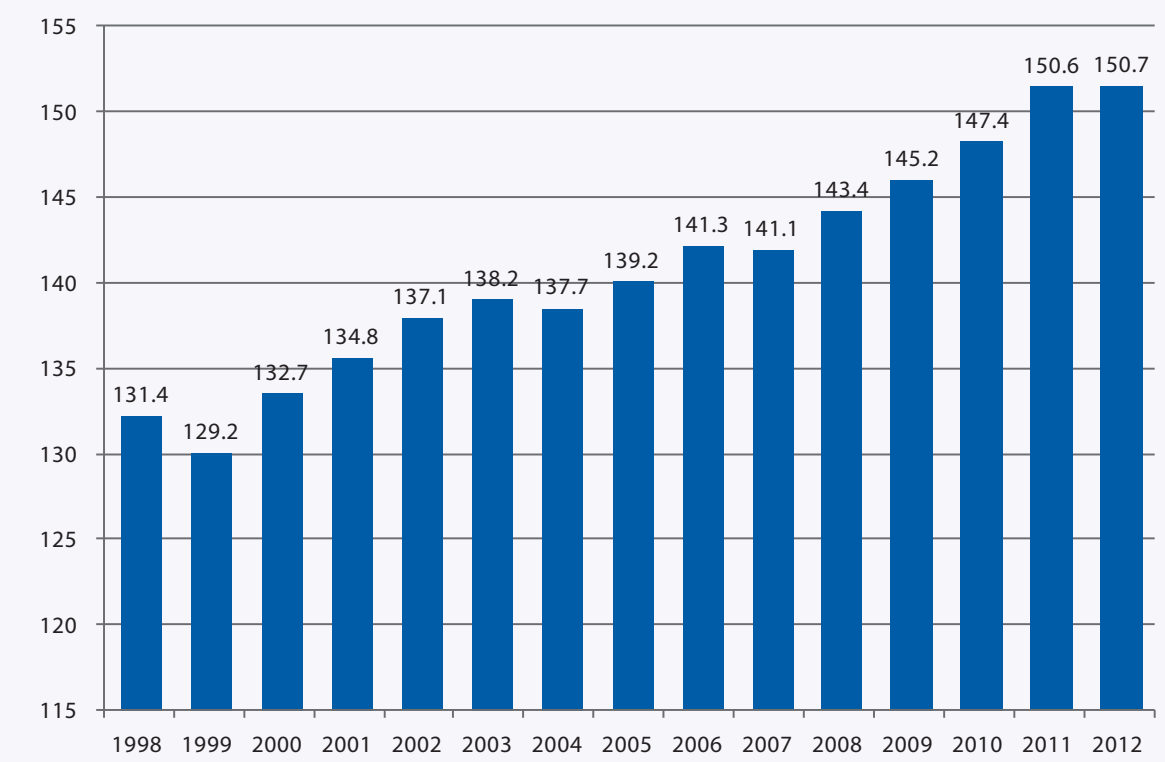

Fuentes: Pemex (2010a y 2013).

\section{Las finanzas públicas transitaron del superávit al déficit}

La reforma energética estuvo acompañada de cambios a la legislación presupuestal que entre 2009 y 2012 tuvieron un gran impacto en el saldo de las finanzas públicas. Durante 


\section{Gráfica 3}

Inversión de capital de Pemex

(Miles de millones de pesos) el último trimestre de 2008, el Congreso hizo modificaciones a la Ley Federal de Presupuesto y Responsabilidad Hacendaria (LFPRH), previas a la aprobación de la Ley de Ingresos 2009, que le permitieron convertir en deuda pública los Programas de Inversión con Impacto Diferido en el Ejercicio del Gasto (PIDIREGAS) de dicha entidad. Estos ascendían a 178 mil millones de pesos a fines de 2008 (gráfica 3), equivalentes a unos 14 mil millones de dólares al tipo de cambio prevaleciente, y habían sido creados en 1997 con objeto de permitir a la iniciativa privada participar en el financiamiento de la inversión de las entidades de mayor tamaño, Pemex y la Comisión Federal de Electricidad (CFE).

Lo más importante de esto es que, mientras en 1998 los PIDIREGAS representaron $39 \%$ de la inversión total en capital de Pemex, para 2002 ya habían llegado a $72 \%$ y en 2008 a 88\%. Es decir, en una década el gobierno federal transfirió al sector privado casi el total de los compromisos de inversión de Pemex. Y unos días antes de que aparecieran los decretos de la reforma energética, el Congreso ya había negociado que dichos compromisos de pago se convirtieran en deuda pública, no obstante que durante 11 años SHCP, SENER y Pemex negaron que formaran parte de la deuda de la entidad.

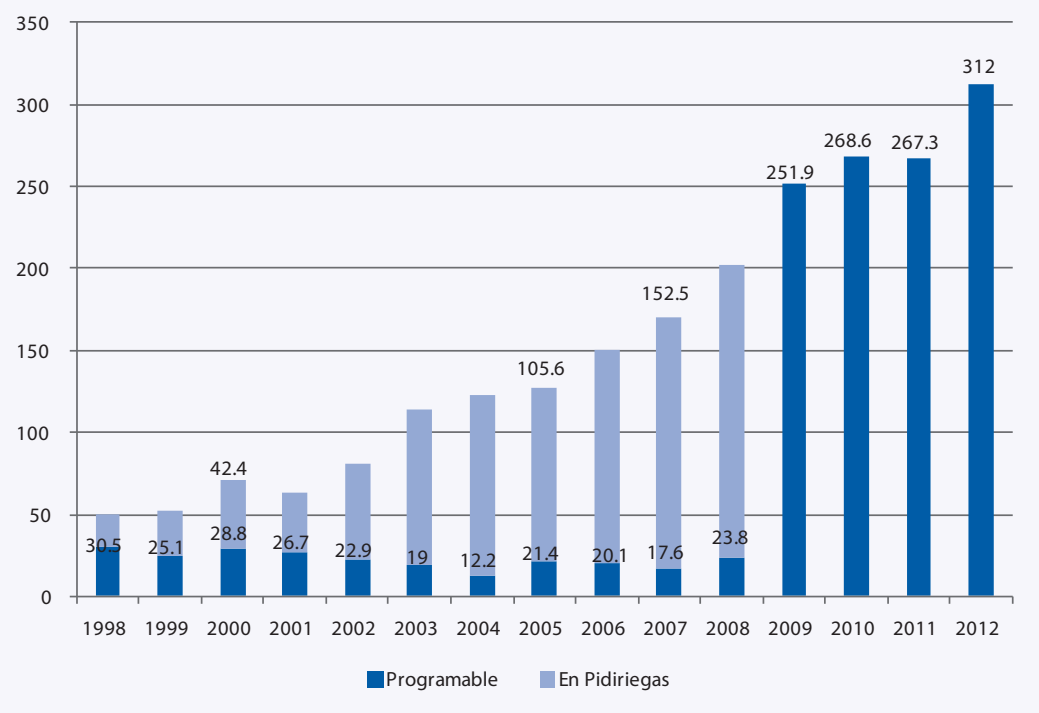

Fuente: con base en Pemex (2010a y 2013).

Previo a la reforma se modificó también la Ley Federal de Derechos en materia de Hidrocarburos, con el fin de permitir a PEP disminuir el pago por concepto del derecho ordinario sobre hidrocarburos. La ampliación en el manejo de los recursos propios de la entidad quedó establecida en la Ley Orgánica de Pemex y Organismos Subsidiarios, la cual aclaró que ésta dispondría de manera progresiva de sus propios recursos para destinarlos a los rubros de inversión, mantenimiento y operación. En el primer año, dicha disponibilidad sería por hasta $35 \%$ de sus excedentes de ingresos propios o hasta 11000 millones de pesos, lo que resultase mayor. Asimismo, Pemex quedaba comprometida a emitir Bonos Ciudadanos por al menos 3\% del total de su deuda de corto y largo plazos.

En los años subsecuentes la entidad podría realizar, si cumplía con los compromisos establecidos por el Ejecutivo Federal, las adecuaciones presupuestarias que considerara, 
salvo las que incrementasen el techo global de gasto o el presupuesto regularizable de servicios personales. En materia de gasto de inversión, mantenimiento y operación en el segundo año podría emplear hasta $50 \%$ de sus excedentes de ingresos propios o hasta 12500 millones de pesos, lo que resultase mayor; en el tercero podría recurrir hasta al $62.5 \%$ de sus excedentes de ingresos propios o hasta 14000 millones de pesos, lo que resultase mayor, y en el tercero hasta $75 \%$ de éstos o hasta 15000 millones de pesos, incluyendo la obligación de emitir, para dicho año, Bonos Ciudadanos por al menos 5\% del total de la deuda de corto y largo plazos de la entidad; en el cuarto podría emplear hasta $\mathbf{8 7 . 5 \%}$ de sus excedentes de ingresos propios o hasta 15000 millones de pesos, lo que resultase mayor. Esto siempre que cumpliera, a juicio del Ejecutivo Federal, las metas establecidas en el Plan de Negocios, mismo que revisarían anualmente, de manera conjunta, SHCP y SENER.

Ante la ausencia de una reforma hacendaria, o por lo menos fiscal, queda claro que la reforma energética condujo automáticamente a un aumento del déficit del sector público. Para hacer menos evidente el problema, a partir de 2009 se separó la inversión de Pemex del saldo económico del sector público. Pero como muestra la gráfica 4, con la inclusión de éste el déficit de dicho sector pasó de prácticamente 0\% del PIB entre 2005 y 2008 a -2.6\% en 2012 (la Presupuestación de SHCP falló, ya que se estimaba que sería de alrededor de -1.8\%). Asimismo, los Requerimientos Financieros del Sector Público (RFSP) pasaron de $-1.5 \%$ del PIB en 2005 y 2006 a $-4.2 \%$ en 2010 y a $-3.9 \%$ en 2012 . Esto indudablemente afectó los planes de estabilización macroeconómica de la administración Calderón; es decir, tuvo que ver mucho con el nivel de las tasas de interés, el INPC y el tipo de cambio.

\section{Gráfica 4}

Posición financiera del sector público con y sin Pemex $-\%$ del PIB-

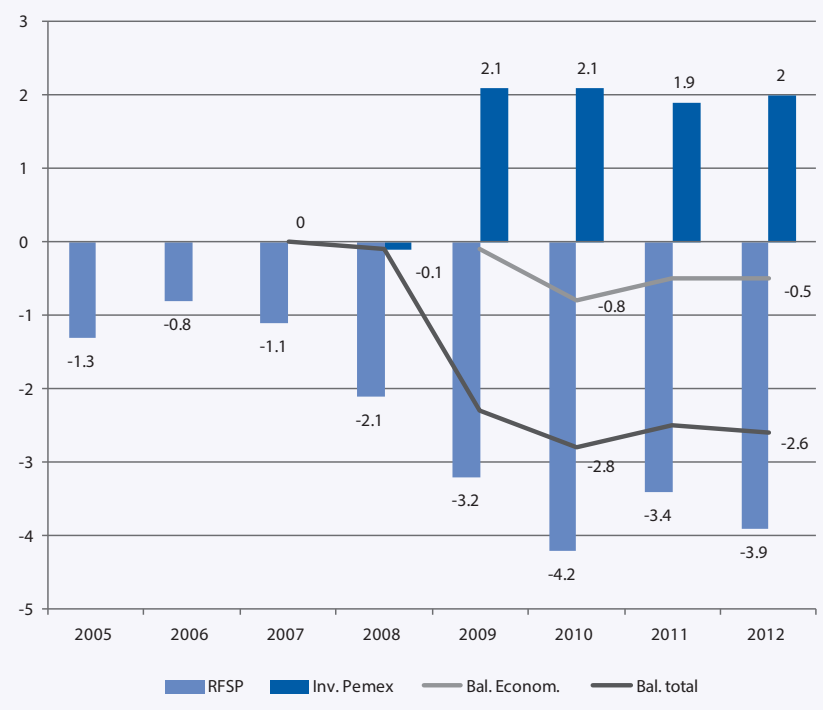

Fuente: con base en SHCP, diferentes documentos. 
Una presión adicional es la transformación de los PIDIREGAS acumulados entre 1997 y 2008 en deuda pública, por acuerdo del Congreso. Experiencias de absorción de pasivos de entidades paraestatales y rescate financiero de empresas privadas existen muchas. Las que posiblemente siguen en la mente de la sociedad son tres: la absorción, sin mayor trámite legislativo, de los pasivos de la Compañía Luz y Fuerza del Centro (CLFC) a fines de los años ochenta y su transformación, en 1994, en Luz y Fuerza del Centro (LFC); el rescate de la banca recién privatizada, a través del Fondo Bancario de Protección al Ahorro (FOBAPROA) y el Instituto para la Protección al Ahorro Bancario (IPAB), a consecuencia de la crisis de 1995, y el rescate de las carreteras de peaje concesionadas, en el mismo año. El saldo de estas deudas, ya sea en su denominación original o canjeadas por bonos, y por tanto imperceptibles a la vista del analista financiero, no parecen haber disminuido en términos absolutos; pero como la mayoría de saldos, han tendido a "licuarse" a través del tiempo (se ha ido reduciendo su participación respecto al PIB; por ejemplo de 12 a $5 \%$ la del IPAB).

La deuda total de Pemex no dejó de crecer entre 1998 y 2012, año en que llegó a 2295.3 miles de millones de pesos, como evidencia la gráfica 5. De dicho saldo más de un tercio se encuentra documentado en divisas y equivale al menos a 60 mil millones de dólares. Debe resaltarse que tan solo entre 2010 y 2012 se contrataron empréstitos que elevaron el saldo total en 788.8 miles de millones de pesos, lo que representa un incremento de $52.3 \%$. La revisión del periodo completo muestra que el saldo se multiplicó 9.2 veces, creció a una tasa promedio anual de $17.1 \%$ y se duplicó a un ritmo promedio de 4 años. Esto por supuesto contrasta con el ritmo de crecimiento de la producción de hidrocarburos y responde mucho a la insolvencia financiera en que quedó la entidad al cierre de la administración, de la cual se hablaba desde la propuesta de reforma.

\section{Gráfica 5}

Saldo de la deuda total de Pemex

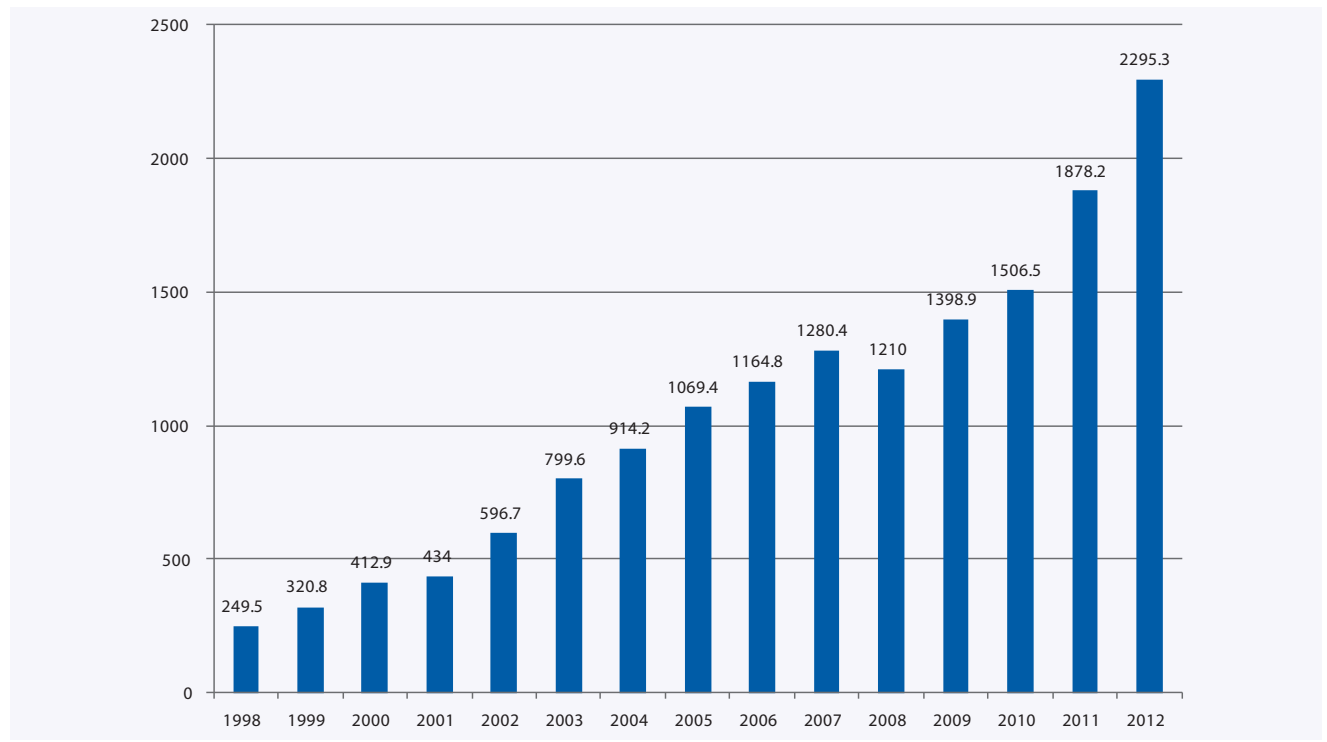

Fuentes: Pemex (2010a y 2013). 
El ritmo de endeudamiento anterior se entiende mejor si se considera que un aspecto importante de la reforma energética consistió en habilitar a Pemex para que, sin requerir autorización de la SHCP, realizara negociaciones oficiales y gestiones informales o exploratorias sobre la posibilidad de acudir al mercado externo de dinero y capitales. De igual manera, se le habilitó para contratar los financiamientos externos que requiriera en moneda extranjera, al igual que obligaciones constitutivas de deuda, sin que éstas fueran obligaciones garantizadas por el Estado Mexicano, pero quedando registradas ante la SHCP. Asimismo, sería responsable de que las obligaciones contratadas no excedieran su capacidad de pago; que los recursos que obtuviera fueran destinados de acuerdo a las disposiciones legales aplicables; que se hicieran los pagos oportunamente y se supervisara el desarrollo de su programa financiero particular.

Como se explicó antes, la reforma condujo a Pemex a cubrir parte de sus necesidades de financiamiento mediante la emisión de Bonos Ciudadanos, es decir títulos de crédito emitidos por el propio organismo que otorgarían a sus tenedores una contraprestación vinculada con el desempeño de la entidad. Los recursos obtenidos se destinarían exclusivamente al financiamiento de obras productivas de la entidad, cuya tasa de retorno esperado sería mayor a la tasa de costo financiero del organismo, así como para operaciones tendientes al mejoramiento de la estructura de su endeudamiento.

Si se parte del endeudamiento que tenía la entidad al cierre de 2009 y 2010 (1 398.9 y 1506.5 miles de millones de pesos, respectivamente), la primera emisión de bonos debería haber sido de 42 mil millones de pesos (3\% del total) y la segunda de 75.3 mil millones ( $5 \%$ del total). Dado lo abultado de la deuda de Pemex, el impacto financiero de los bonos estaba destinado a ser limitado; empero, el público ahorrador habría agradecido el gesto.

En el marco de su mayor autonomía de gestión, así como de su liberalización en materia de contratación de deuda, a fines de agosto de 2011 Pemex hizo público que de los 1200 millones de euros que había erogado para aumentar su participación accionaria en Repsol-Yacimientos Petrolíferos Fiscales (R-YPF), 70\% provenía de colocación de deuda, no obstante el alto saldo de ésta. La Dirección General de Pemex manifestó que dicho apalancamiento no se registraría como deuda de Pemex, sino de la empresa operadora del movimiento, PMI Holdings B.V., que forma parte del grupo PMI, constituido por varias empresas "dedicadas a dar soporte a Pemex para la comercialización de hidrocarburos en el mercado internacional", de las que PMI Holdings B.V. y PMI Holdings Petróleos España, S.L. tienen el carácter de "tenedoras" (PMI, 2007). A la postre, la Secretaría de la Función Pública (SFP) descubrió un fraude asociado con dos empresas globales con operaciones en Ámsterdam, Holanda, misma ciudad donde tiene su sede PMI Holdings B.v. por 24.3 millones de dólares debido a la venta a precio de ganga de gasolina coquer a las empresas de transporte, comercialización y almacenamiento de hidrocarburos globales Trafigura y Gunvor, lo que provocó la inhabilitación de varios funcionarios de PMl.

Además de su permisividad en materia de deuda, la reforma energética omitió fijar como condición explícita al Director General de Pemex informar al Consejo de Administración sobre aumentos en la participación de capital de ésta en empresas extranjeras, no obstante que subyacía en los propósitos de la reforma la instauración de un gobierno corporativo. En el caso de R-YPF, dicha omisión generó un enorme malestar que por lo 
menos dos consejeros profesionales hicieron explícito ante los medios. Bajo esta presión, más la generada en España, ya que el aumento de Pemex en la participación accionaria de R-YPF también involucró un acuerdo de aquélla con la constructora Sacyr Vallehermoso (SyV), empresa que ostentaba 20\% del capital social de R-YPF, el entonces Director se vio orillado a reconocer que, aunque había informado con anticipación al Presidente de la República y a sus autoridades sectoriales de la operación, consideraba un error no haber hecho lo mismo con el Consejo. Esto por supuesto no lo exime de haber sentado un precedente inusitado: la inversión de recursos de la industria petrolera de México en el exterior a pesar del alto nivel de deuda externa de la entidad, la ausencia de consulta al Consejo de Administración, y el intento de apoderamiento de la empresa extranjera en cuestión (R-YPF) mediante la alianza de Pemex con Syv, que hubo de disolverse en apenas cuatro meses, es decir en enero de 2012. La estrategia era evidente y los españoles no se involucraron en ella: hacer una Oferta Pública de Adquisición (OPA) a R-YPF en virtud de que la participación accionaria conjunta de Pemex y Syv estaba a unas décimas del piso legalmente necesario de 30\% (Gutiérrez, 2012).

\section{Se inició la instrumentación de contratos con terceros}

La práctica no escrita de Pemex previa a la reforma permitía a la entidad contratar con empresas privadas cerca de una séptima parte (15\%) del valor de sus proyectos de inversión, sin necesidad de convocar a licitación. Esta discrecionalidad actuó como catalizador del desvío de recursos, de los que la Auditoría Superior de la Federación informó al revisar la Cuenta Pública de cada año (ASF, 2011). Cualquiera esperaría que la reforma terminara con estas prácticas; empero, la nueva Ley Orgánica de Pemex y sus Organismos Subsidiarios establecía que, en materia de autonomía de gestión hacia los contratistas, Pemex y dichos organismos, de acuerdo con sus respectivos objetivos, podrían celebrar con personas físicas o morales toda clase de actos, convenios, contratos y suscribir títulos de crédito, manteniendo en exclusividad la propiedad y el control del Estado Mexicano sobre los hidrocarburos, con sujeción a las disposiciones legales aplicables, a partir de tres tipos de contratos: licitación pública, adjudicación directa e invitación restringida.

Los contratos de licitación pública tienen un carácter convencional: inician con la publicación de la convocatoria y concluyen con la emisión del fallo o, en su caso, la declaratoria de cancelación del procedimiento debido a desinterés o falta de idoneidad de los participantes.

Los contratos de adjudicación directa pueden ser de tres tipos: a) vinculados directamente con la remediación de derrames, emisión de gases tóxicos o peligrosos, vertimiento irregular de hidrocarburos o cualquier otro incidente que ponga en riesgo a los trabajadores, a la población, el medio ambiente o las instalaciones utilizadas por Pemex o sus organismos subsidiarios, que sean consecuencia de accidentes, sabotajes, robo, otros actos dolosos $u$ otros eventos que requieran de atención inmediata; $b$ ) de servicios de fedatarios públicos, peritos y de representación en procesos judiciales o administrativos, y c) de refaccionamiento o servicios relacionados con la instalación, mantenimiento o conservación de equipos industriales del fabricante original del equipo o maquinaria, a fin de mantener la garantía técnica del mismo. 
Los contratos por invitación restringida (a por lo menos tres personas o instituciones), con el propósito de desarrollar innovaciones tecnológicas para Pemex y sus organismos subsidiarios, así como para obtener servicios de estudios de ingeniería, servicios de consultoría, estudios diversos, asesorías, investigaciones y capacitación.

Aunque los contratos de adjudicación directa e incluso los de invitación restringida propiciaban la discrecionalidad de Pemex en la obtención de servicios de terceros en una amplia gama de actividades, lo que implicaba el manejo unilateral de una enorme cantidad de recursos, la reforma se opuso, al menos en su redacción, a los contratos de riesgo, máxima aspiración del Ejecutivo y de las compañías petroleras. De acuerdo con la práctica internacional, dichos acuerdos permiten al contratista recibir bajo concesión un área delimitada de terreno o lecho marino para su exploración y explotación y o bien hacerse de una parte de los hidrocarburos extraídos en pago a su expertise, devolviendo al Estado del país en que operan la parte restante, o bien quedarse con el total de recursos y pagar las regalías e impuestos correspondientes. Aunque el texto original de la reforma energética no cerró explícitamente el paso a la concesión de áreas para su explotación por parte de terceros, sí lo hizo con relación a la remuneración de éstos mediante la retribución en otra forma que no fuera dinero en efectivo. Asimismo, negó apertura al capital privado, nacional y extranjero, en las áreas de refinación, distribución por ducto y almacenamiento de petroliferos, incluyendo estaciones de servicio.

La propuesta de apertura al capital privado contenida en el documento original de reforma, que envió la SENER (2008) a la Cámara de Senadores, se sustentaban en la insuficiencia de recursos financieros de Pemex para invertir en toda la gama de actividades involucradas en una industria que, por estar verticalmente integrada, había dejado de gozar del grado de operatividad que tuvo incluso hasta unos años después de su nacionalización, en 1938. El Legislativo consideró que dicha opción debía moderarse, sobre todo porque no se estaba modificando el artículo 27 constitucional, sino una serie de leyes secundarias. Como después manifestó un miembro de la Comisión de Energéticos del Senado de la República: "Se aprobó lo políticamente posible, no lo Ejecutivamente deseable".

Debido a las limitaciones señaladas, la parte de la reforma energética referida a los contratos a terceros fue una de las que más decepcionó a la iniciativa privada, ya que desde principios del siglo tanto el Ejecutivo en turno como los directores de Pemex habían asegurado en foros internacionales que dicha entidad se abriría a la inversión. Todavía en 2010 el Presidente Calderón y el Director General de Pemex seguían insistiendo en diversos foros nacionales e internacionales (Tula, Hidalgo; Davós, Suiza; la Jolla, California) que la apertura total sólo era cuestión de tiempo, y que seguramente la habría de consolidar con una reforma de segunda generación. ${ }^{8}$

8 En respuesta a la crisis financiera internacional de 2008-2009, que provocó una severa contracción de la economía mexicana, el presidente Calderón propuso a la sociedad, en su mensaje a la nación del primero de septiembre de 2009 (Calderón, 2009), la instrumentación de cinco reformas económicas de segunda generación. La energética se refería a nuevas modificaciones al marco legal de la industria petrolera que permitieran flexibilizar la participación de la iniciativa privada en la exploración y explotación de hidrocarburos, lo mismo en tierra firme que en el fondo del océano, así como en la refinación de petróleo y el mantenimiento de las instalaciones y ductos de la paraestatal, sin descartar la posibilidad de una nueva reclasificación de productos de la industria petroquímica primaria a secundaria. Es probable que, al observar que las posibilidades de al menos iniciar negociaciones sobre este segundo paquete con el 
En este contexto, instituciones privadas que intentan liderar grupos de análisis e inversión, como el Consejo Coordinador Empresarial (CCE, 2008) y el Centro de Estudios Espinoza Yglesias (CEEY, 2008) manifestaron abiertamente que dicha reforma no pasaba de ser un ejercicio insuficiente. Paradójicamente, la mayoría de académicos agrupados en distintos centros de investigación, así como constitucionalistas y algunos ingenieros comprometidos con la industria vertieron una opinión similar, aunque en el sentido de que estaba bien que Pemex no se abriera a la inversión privada, sobre todo extranjera, y que habría que velar porque en su proceso de instrumentación no se excediera lo que los decretos establecían.

El debate no terminó ahí: interpretando los decretos, que se publicaron sin que las facciones políticas en el Congreso hubieran logrado un consenso en puntos específicos como el antes señalado, el Ejecutivo Federal y Pemex pretendieron, y finalmente lograron poner en funcionamiento una nueva figura de contratos, los incentivados, con cuyos alcances se buscaba convencer a las empresas privadas de participar en labores de exploración y explotación de hidrocarburos. Aunque los diputados de izquierda apelaron dicha pretensión ante la Suprema Corte de Justicia de la Nación (SCJN), ésta finalmente falló, a principios de marzo de 2011, a favor de Pemex, entidad que desde meses antes los había exhibido internacionalmente bajo el nombre de Contratos Integrales de Exploración y Producción (CIEP) (Pemex, 2010d). La justificación de la SCJN fue que no atentaban contra la soberanía nacional y no eran violatorios del artículo 27 constitucional en el ámbito del petróleo y sus derivados.

Los críticos de la reforma, tanto del lado empresarial como académico y laboral, coinciden en que no se cumplieron las expectativas de la sociedad en torno a que el Senado de la República negociara un paquete que sirviera para reforzar los encadenamientos de Pemex hacia adelante y hacia atrás, a fin de contribuir al desarrollo industrial privado, la generación de empleos y el estrechamiento de lazos entre la investigación científica y el desarrollo tecnológico. Asimismo, se lamentaron de que en los documentos que dieron cuerpo a la reforma no se hubiesen incluido al menos algunas de las preocupaciones que ellos mismos habían manifestado en los foros de consulta convocados por el Senado de la República a mediados de 2008.

Más aún, una vez puestos en operación los CIEP, a partir de marzo de 2011, primero con la licitación de tres pozos maduros en Tabasco, pertenecientes a la zona Sur-Magallanes, Santuario y Carrizo-, y después en la zona Norte terrestre -Altamira, Pánuco, San Andrés y Tierra Blanca- y Norte Marina -Arenque y Atún- las voces disidentes de los académicos, constitucionalistas e ingenieros se hicieron más evidentes. A ellas se sumó la de por lo menos un consejero profesional de Pemex, Rogelio Gasca Neri, quien en su Voto Razonado del 15 de noviembre al Consejo de Administración de Pemex manifestó lo siguiente:

A lo largo del proceso de licitación (de los tres pozos maduros de la zona Sur) sucedieron
diversos eventos que por su trascendencia, así como por las lecciones que pueden aportar,
no debemos pasar por alto:

Congreso eran inexistentes, el Ejecutivo decidió concentrar su atención en el contenido de los contratos que firmarian Pemex y sus empresas subsidiarias con terceros. 
"Se presentaron varias controversias constitucionales, tanto por la Cámara de Diputados como por Estados y Municipios, sin que la SCJN resolviera el fondo del asunto, ni mucho menos aprobara los contratos. La SCJN desestimó la personalidad de quienes presentaron la controversia, y en otro caso estimó que algunos artículos del Reglamento de la Ley de Petróleos Mexicanos no violaban la Constitución. Pero en ningún momento aprobó o dio el visto bueno a estos contratos.

"Se recibieron muchos y diversos comentarios de las áreas internas de Petróleos Mexicanos y por parte de compañías petroleras y de servicios, nacionales y extranjeras, interesadas en estos contratos, así como más de 2,000 en las juntas de aclaraciones celebradas con los contratistas que compraron las bases de licitación. Como resultado, las bases de licitación y el contrato tuvieron muchas e importantes modificaciones por parte de PEP.

"Yo mismo expresé mi punto de vista y cuestionamientos a lo largo de todo el proceso de licitación: desde que se publicó el modelo de contrato y las bases, cuando se modificaron las mismas en varias ocasiones, hasta que se adjudicaron los contratos. Estas preocupaciones fueron dirigidas tanto al Director General como al Director de PEP, marcando siempre copia al Secretario de Energía. También mantuve enterados a mis compañeros Consejeros Profesionales...

“...En el caso de carrizo la licitación la ganó una empresa que el día de la firma del contrato se autoeliminó al incumplir con las condiciones de garantías y poderes. Ante esta circunstancia, PEP asignó el contrato a la única otra empresa que participó y que había ofertado una tarifa por barril producido sensiblemente mayor, de casi el doble, 5.03 y 9.40 dólares por barril, respectivamente. ${ }^{9}$

"...Considero que para estar en condiciones de analizar los nuevos contratos incentivados para seis áreas en la región Norte se requiere además que los comités de Apoyo al Consejo ... analicen y evalúen esta primera ronda minuciosamente y den su opinión en las áreas de su competencia.

"He revisado minuciosamente la última versión de las bases de licitación y del modelo de contrato para Magallanes, Santuario y Carrizo y he constatado que las nuevas versiones contienen numerosos cambios...sin que ninguno sea en beneficio para Pemex (y que habrían requerido) la aprobación del Consejo.

“...En mi opinión, y en la de varios de ustedes, los tres contratos para la región Sur que se firmaron contienen un gran número de cambios que impactan los parámetros, términos y condiciones del contrato original aprobado por este Consejo que no debieron ser modificados sin la discusión y el consentimiento del Consejo de Administración de Pemex, como lo establecen la Ley de Pemex, las Disposiciones Administrativas de Contratación y el Acuerdo CA-131/2010 del Consejo. Esto último no es una mera formalidad sino que se trata de apegarse al marco legal vigente. Esta situación es suficiente para no votar por los seis contratos de la región Norte, mientras no se discutan y aclaren todos los puntos que tengamos los consejeros y como resultado de ello se tenga un dictamen del Abogado General de Pemex avalando el contrato a firmarse (Gasca Neri, 2011).

9 Las adjudicaciones originales de los pozos en la región Sur correspondieron a una empresa británica, Petrofac Facilities Management, que se quedó con los dos mayores proyectos, Santuario y Magallanes, y una mexicana, Administradora de Proyectos de Campo S.A. de C.V., a la que se había asignado el de menor envergadura, Carrizo (Pemex, 2011d). Finalmente, ésta se desentendió y, por default, la asignación se hizo a la empresa que había quedado en segundo lugar, la estadounidense Dowell Schlumberger. 
Los principales puntos de controversia apuntados por Gasca Neri y que por obvio de espacio no se analizan a detalle son: los altos precios que garantiza Pemex a las empresas productoras por cada barril de petróleo que extraen de sus áreas asignadas (tarifa míni$\mathrm{ma}$ ), a pesar de las malas experiencias internacionales al respecto; la facilidad con que se modifican los contratos al transitar de la región Sur a la Norte; el tiempo de duración de su otorgamiento, que pasa de 25 años en la primera región a 30 en la segunda (de ahí su carácter de multianuales); la subestimación de la capacidad productiva de las regiones; la ligereza con que la SCJN trató las controversias constitucionales de quienes se oponían a los contratos; la desestimación de las autoridades de Pemex respecto a los puntos de vista tanto de las empresas concursantes como de los consejeros profesionales durante el primer proceso de licitación; la forma marginal y oscura en que una filial de una filial de Pemex participa con apenas 10\% de las actividades del contratista; la reducción a un mínimo de las obligaciones de dicho contratista en materia de capacitación de personal y de transferencia de tecnología; su casi nula responsabilidad con relación a la preservación del medio ambiente; la facilidad con que puede desistir de continuar el proyecto, independientemente de su grado de avance, mientras para PEP es virtualmente imposible revocarlo; la obligación de Pemex de comprar al contratista toda su producción, aunque no pueda procesarla, lo que equivale a pagar a la empresa por no trabajar; el derecho implícito del contratista a participar de la producción, pues no se le prohíbe explícitamente a hacerlo, lo que era un compromiso supremo de los contratos objetivo, y la incapacidad para sujetar al contratista a las mismas restricciones que Pemex en materia de caso fortuito, o fuerza mayor, es decir de dejar de producir (o comprar) por razones de huelga o conflictos laborales con el sindicato.

Evidentemente lo que denuncia Gasca Neri es una práctica legislativa común, que por lo visto también se lleva a cabo en las empresas paraestatales. Pruebas existen muchas; una de ellas es la reducción de los ingresos de los jubilados y pensionados del IMSS y del ISSSTE mediante la modificación progresiva del estatuto que los exentaba del pago del Impuesto sobre la Renta (ISR). Esto lo llevó a cabo subrepticiamente la Cámara de Diputados a partir de fines de la administración Fox argumentando que las pensiones eran una extensión del salario y, por tanto, deberían sujetarse al mismo régimen impositivo de los trabajadores en activo. El primer paso fue decantar el concepto de prestaciones de ley, con que siempre se habían caracterizado las jubilaciones y pensiones, independientemente de su monto. Así, entre 2008 y 2010 se hicieron ajustes legislativos a la fracción III del Artículo 109 de la Ley de Ingresos, hasta establecer que las jubilaciones y pensiones superiores a nueve salarios mínimos en el Área Geográfica A (SMAGA) dejaban de estar exentas del Impuesto Sobre la Renta (SHCP, 2010). Posteriormente, la SCJN fijó dicho nivel en 15 SMAGA.

Los CIEP parecían reflejar el sentimiento de la administración Calderón en el sentido de que, entre más rápido se retirara el gobierno de la industria petrolera, más rápido se desarrollaría ésta. Coincidentemente, al dar posesión a una nueva titular de Petrobras, Maria Graças Foster, la Presidenta de Brasil, Dilma Rousseff, expresó en febrero de 2012 lo siguiente: "Petrobras es poderosa a escala mundial y felizmente sobrevivió a todos los vientos de privatización y tiene un papel fundamental en nuestro modelo de crecimiento" (AFP y EFE, 2012). Asimismo recordó que la meta de la empresa era aumentar su producción de petróleo crudo equivalente de 2020 MBD en 2011 a 6000 MBD en 2020. 


\section{No se estimuló la productividad}

La reforma no coadyuvó a aumentar la productividad de Pemex, tal vez porque desde el inicio de la administración se reconocía, por una parte, que el número de trabajadores de la entidad contabilizados en 2007 -147 275- era de los más altos de las empresas petroleras del mundo, y por otra, la producción de hidrocarburos iba en descenso desde fines de 2004, ubicándose en 4570 miles de barriles de petróleo crudo equivalente (MBPCE) en 2007. Con ello, el producto por persona ocupada en dicho año fue de 31 barriles diarios de petróleo crudo equivalente (BDPCE). Mientras tanto, una empresas petrolera muy exitosa, Exxon Mobil, produjo en el mismo año 4100 MBDPCE con 83 mil trabajadores (Exxon Mobil, 2008), con lo que su producto por persona ocupada fue de 49.4 BPCE. Es decir, en 2007 el producto por persona ocupada fue, en volumen, 1.6 veces mayor en Exxon Mobil que en Pemex. La brecha se ahondaba al tomar como referencia el valor de las ventas totales: 404552 millones de dólares por parte de Exxon Mobil en 2007 contra 93140 millones de dólares por parte de Pemex, lo que arrojaba un producto por persona ocupada de 5 millones de dólares anuales en la primera empresa y de apenas 632 mil dólares en la entidad mexicana. Así, en términos de valor, el producto por persona empleada en Exxon Mobil fue, en 2007, 8 veces mayor al de Pemex.

Tampoco propuso la reforma modificar la distribución de esa fuerza de trabajo, lo que es excesivamente irracional ya que, tan solo en el corporativo de Pemex, los servicios médicos, las telecomunicaciones y otras actividades administrativas laboraban, en 2007, 44078 empleados, lo que quiere decir que, sin contar a los directivos y oficinistas de las áreas productivas, por cada 2.3 trabajadores de campo la entidad tuvo un administrativo (Pemex, 2008). Este inmovilismo por supuesto estaba sustentado en el contrato colectivo de trabajo firmado con el Sindicato Único de Trabajadores Petroleros de la República Mexicana (SUTPRM), el cual no se modificó con la reforma, como tampoco lo hizo la relación entidad-sindicato.

\section{No se apoyó el desarrollo tecnológico}

En materia de desarrollo tecnológico, la reforma prometió mucho más de lo que se plasmó en el papel. La Ley Orgánica de Pemex y Organismos Subsidiarios sólo establecía que dichas entidades definirían una estrategia para apoyar el desarrollo de proveedores y contratistas nacionales como parte del Plan Estratégico Integral de Negocios, la cual debería incluir un diagnóstico de la participación de los proveedores y contratistas mexicanos en las obras, las adquisiciones y arrendamientos de bienes y servicios, así como objetivos específicos y metas cuantitativas anuales a alcanzar del grado de contenido nacional en bienes, servicios y obras, respetando lo establecido en los tratados internacionales. Dicho contenido nacional se ubicaría en un mínimo de $25 \%$; es decir que se fijaba un tope de participación de $75 \%$ a los proveedores y contratistas extranjeros. Aunque parezca risible, esta cifra es similar a la que practicaba Pemex antes de la reforma, como reconoció la propia SENER, cuando ya habían aparecido los dictámenes, ${ }^{10}$ e inferior, por citar un ejemplo, al

10 Quien fuera Secretaria de Energía hasta principios de 2011, Georgina Kessel, reconoció ante un grupo de empresarios mexicanos, a fines de 2008, que históricamente la participación de la inversión 
valor agregado obligatorio de proveedores nacionales de autopartes en la elaboración de automóviles que se negoció en el Tratado de Libre Comercio de América del Norte (TLCAN): 34\% para los primeros cinco años de vigencia de éste (Blanco, 1994:180).

Asociado a lo anterior, la reforma promovería el desarrollo de las pequeñas y medianas empresas y, a fin de llevar un registro de los avances de la estrategia, Pemex y sus organismos subsidiarios formularían un plan anual de compras a pequeñas y medianas empresas y registrarían todas sus cuentas por pagar en el Programa Cadenas Productivas de Nacional Financiera SNC (NAFIN). Para ello, Pemex y sus organismos subsidiarios se apoyarían en un área especializada de promoción e incorporación de nuevos contratistas y proveedores nacionales.

Por tratarse de una industria verticalmente integrada, las expectativas de los mexicanos, expresadas tanto en los foros organizados por el Senado de la República durante la primera mitad de 2008 como por instituciones de educación superior y de la iniciativa privada, eran que el texto de la reforma apoyaría la potenciación de las capacidades tecnológicas del país, desde la investigación científica y tecnológica hasta el diseño y aplicación de software, hardware y prototipos para la exploración y explotación de hidrocarburos en campos complejos, a partir de las capacidades existentes en el Instituto Mexicano del Petróleo (IMP) y los centros de investigación y educación superior del país. No hacerlo se consideró un desacierto para la creación de capacidades tecnológicas propias.

\section{Fue una reforma inconclusa}

El Plan Nacional de Desarrollo 2007-2012 (Presidencia, 2007) estableció que, de no aprobarse tres reformas estructurales básicas (fiscal, energética, laboral) no se lograrían incrementar adecuadamente durante el sexenio la inversión y la productividad y, por tanto, el crecimiento del PIB promedio entre 2007 y 2012 sería de 3.5\% y el del PIB per capita de $2.4 \%$. Empero, en caso de concertarse éstas, dichas tasas se ubicarían en 4.2 y $3.1 \%$, respectivamente (pp. 84-85), y se crearian por lo menos 800 mil empleos formales cada año (p. 104).

Al finalizar el periodo sexenal, y con las tres reformas económicas originalmente propuestas aprobadas por el Congreso, resultó evidente que el sexenio 2007-2012 fue el de menor crecimiento promedio anual (2.3\%) desde el de Miguel de la Madrid (0.3\%), como se muestra en el cuadro 2. A esto hay que agregar el hecho de que la generación de empleos formales se ubicó en apenas $40 \%$ de las 800 mil nuevas plazas anuales prometidas en el PND 2007-2012 y en un tercio del millón de personas que se incorporan anualmente al mercado de trabajo. Esto se corrobora a partir del número de asegurados al IMSS, que se ubicó en 16.1 millones al cierre de 2012, contra 13.7 millones al cierre de 2006, lo que implica que en promedio se generaron durante el sexenio 400 mil plazas cada año; es decir que de cada 10 personas que ingresaron al mercado de trabajo seis se fueron a la informalidad o el desempleo y sólo cuatro a la formalidad. Los años más desfavorables fueron 2008 y 2009, pues no se contó con una política contracíclica, y apenas en 2010 se

extranjera en la inversión total de la industria petrolera de México había sido de 70\%. Esto generó gran inconformidad, ya que la declaración fue posterior a la aparición de los dictámenes y cuando estaban por publicarse los decretos. 
regresó a los más de 14 millones de asegurados que se tenían en 2007, como corroboran las estadísticas de la STPS (2012).

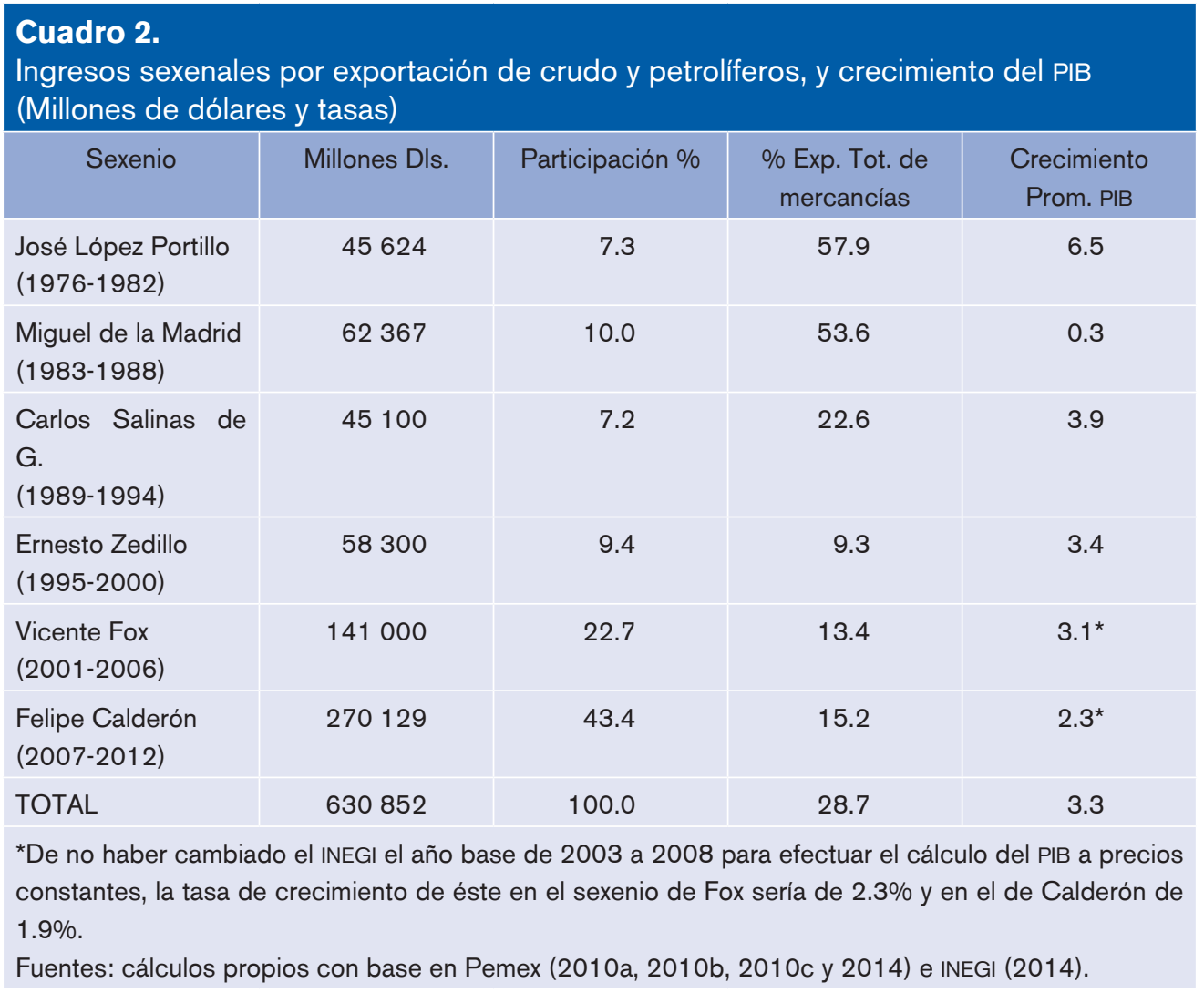

Lo anterior contrasta con la situación de la industria petrolera, gran beneficiaria del entorno internacional. Al tomar en cuenta que el precio internacional del petróleo crudo de exportación promedio sexenal fue varias veces mayor en 2007-2012 a los periodos anteriores, superando desde marzo de 2011 hasta mayo de 2012 la marca de 100 dólares por barril, es evidente que, en términos de las divisas captadas, el efecto precio compensó con creces el efecto Cantarell (caída de más de $80 \%$ en la producción del principal yacimiento del país entre 2004 y 2012). Ello permitió que las exportaciones conjuntas de petróleo crudo, petrolíferos y petroquímicos ascendieran a 270.1 miles de millones de dólares en el sexenio y que la participación de éstas en las exportaciones totales pasara de 9.3\% promedio en el gobierno de Zedillo a 15.2\% en el de Calderón.

Cabe destacar que al acumular las exportaciones de Pemex desde el sexenio de López Portillo hasta el de Calderón (1976-2012), como se hace en el último renglón de la segunda columna del cuadro 2, su valor corriente asciende a casi 630.85 miles de millones de dólares. De esta cantidad, $43.4 \%$ fue recibido por el gobierno de Calderón y $22.7 \%$ por el de Fox. Es decir que entre ambos se adjudicaron dos terceras partes de las divisas generadas por la industria petrolera desde su resurgimiento en los años setenta. 


\section{Conclusiones}

A la decepción generada durante los años posteriores a la aprobación de la reforma energética de 2008 deben sumarse los magros alcances de la reforma fiscal de 2007, completamente insuficiente para las necesidades de financiamiento del gasto público e incapaz de elevar el coeficiente de tributación. Una lección importante de esto es que, para que las reformas estructurales sean capaces de devolver viabilidad a los países e impulsar su crecimiento de largo plazo, como sucedió con Chile, España e Irlanda entre los años ochenta y noventa, también deben tomar en cuenta a los consumidores. Entre mayor sea la capacidad de gasto de la población y más se incorpore ésta al mercado, más contribuirá a las ventas y los impuestos. Lo mismo es válido para los ingresos que reciben los trabajadores cuando alcanzan la jubilación, estrato de la población que crece muy rápido. Empero, las reformas al sistema de pensiones del IMSS (1997) y del ISSSTE (2007) fueron concebidas de tal forma que apenas garantizan una tasa de reemplazo (porcentaje de las remuneraciones del último año laborado que recibe un trabajador al momento de jubilarse) de $32 \%$, el nivel más bajo de los países miembros de la OCDE (2011).

A esta debilidad hay que agregar otros inconvenientes. El primero es que los salarios promedio han caído persistentemente en términos reales desde 1981, para ubicarse en 2012 45\% abajo del nivel alcanzado 30 años antes. El segundo es que la masa salarial al cierre de dicho año pesaba apenas $27 \%$ en el PIB, mientras en países como Estados Unidos ascendía a $65 \%$, lo que por una parte indica un gran desequilibrio en la distribución del ingreso y por otra manda a los trabajadores el mensaje de que el mercado interno dejó de interesar al gobierno y a los patrones por lo menos desde que se iniciaron las reformas estructurales, en 1983. El tercero es que, dadas las constantes entradas y salidas de los trabajadores al mercado formal (el único que cuenta para alcanzar la jubilación) junto con el incremento en el número de años y edad requeridos para jubilarse que establecen las reformas a las leyes del IMSS y el ISSSTE así como la práctica del outsourcing y la creación del seguro popular, la proporción de trabajadores que lograrán jubilarse disminuirá con el tiempo. En estas condiciones, los trabajadores no sólo no apoyaron la reforma laboral aprobada por el Congreso en noviembre de 2012, sino que sus líderes reunieron firmas para tratar de revertirla, junto con otras reformas estructurales.

Un punto adicional es que el éxito de las reformas no sólo depende de transformaciones jurídicas, sino de que el sector público se comprometa con la inversión productiva. Si se transfiere la propiedad de las empresas paraestatales a la iniciativa privada, incluyendo bancos, hospitales, servicios de limpieza, hidrocarburos, electricidad, y en el futuro posiblemente servicios de agua y carcelarios, y se desregulan completamente los mercados con la idea de que ello será suficiente para atraer a los inversionista, se pasa por alto la necesidad de infraestructura, sin la que ninguna inversión privada progresa, como corrobora el modelo asiático (Stiglitz, 1996). Si algún correlato existiera en la historia de México, ese sería el periodo del milagro mexicano, cuando el Estado tomó la iniciativa en inversiones cruciales para el desarrollo: industrias pesadas (extractiva, siderúrgica, química y petroquímica); de apoyo a la agricultura (sobre todo fertilizantes); energéticos (petróleo y electricidad); transportes (ferrocarriles, carreteras, puertos y aeropuertos); educación, salud, centros de investigación y, por supuesto, banca de desarrollo, cuyo apalancamiento incidió en el desarrollo 
industrial, agropecuario y del pequeño comercio (Ortiz Mena, 1998). Hoy día la política social y la seguridad pública absorben muchos de esos recursos, pero también la corrupción ha aumentado, como evidencia la industria petrolera; de modo que hay posibilidades de eficientar las erogaciones.

Son numerosas las áreas en que se requiere la inversión pública para estimular a la privada: puertos marítimos, aeropuertos, carreteras, ferrocarriles, irrigación, escuelas tecnológicas, educación a distancia, centros de salud, potabilización de agua, crédito para el desarrollo, energía. Esta inversión se debe complementar con medidas regulatorias severas en sectores privatizados, particularmente el financiero, responsable de la recesión de 1995 en México y 2008 en Estados Unidos; el minero, donde el otorgamiento de concesiones ha resultado lesivo para el país; el energético, por lo menos en las áreas ya liberalizadas, como gas natural, tendido y operación de poliductos, y prestación de servicios de exploración y producción, y el de tecnologías de la información y la comunicación (satélites, internet, telecomunicaciones, telefonía), que inciden en toda la economía.

Concretamente, frente a las reformas estructurales, se requieren esfuerzos excepcionales en materia de inversión de infraestructura, medidas regulatorias estrictas y ampliación del mercado interno. Si no se promueve esto, no sólo se tirarán por la borda las posibilidades de desarrollo del país, sino que la oposición social a las reformas irá en aumento lo que incidirá tanto en su aprobación como en su instrumentación.

\section{Bibliografía}

AFP y EFE (2012), "Petrobras con nueva titular", Excélsior, 14 de febrero.

Auditoría Superior de la Federación (ASF) (2011), en www.asf.gob.mx, consultado en junio de 2011.

Bazdresch, Carlos y Santiago Levy (1992), "El populismo y la política Económica de México, 1970-1982", en

Dornbusch y Edwards (1992), Macroeconomía del Populismo en América Latina, Lecturas de El Trimestre Económico No. 75, México, FCE.

Blanco Mendoza, Herminio (1994), Las Negociaciones Comerciales de México con el Mundo, México, FCE. British Petroleum (BP) (2010), BP Statistical Review of World Energy, Londres, junio.

Calderón Hinojosa, Felipe (2009), Mensaje a la Nación, 1 de septiembre, www.presidencia.gob.mx, consultado en enero de 2010.

Carrillo Anaya, Laura y Juan Pablo Guerrero (2004), "Los salarios de los altos funcionarios en México desde una perspectiva comparativa", documentos internos, CIDE, México.

Centro de Estudios Espinoza Yglesias (CEEY) (2008), opiniones sobre la reforma energética, en www.ceey.org.mx, consultado en junio de 2009.

Consejo Coordinador Empresarial (CCE) (2008), opiniones sobre la reforma energética, en www.cce.org.mx, consultado en junio de 2009.

Comisión Nacional de Hidrocarburos (CNH) (2010), diferentes documentos evaluatorios sobre reservas y producción de hidrocarburos, en www.cnh.gob.mx, consultado en noviembre de 2011.

(2013), Reporte de Indicadores de Producción de hidrocarburos, en www.cnh.gob.mx, consultado en agosto de 2013.

(2012), "Reservas de Hidrocarburos al 1 de enero de 2012", Boletín de Prensa, marzo 6, México. 
Diario Oficial de la Federación (DOF) (2008), Decretos de la reforma energética, 28 de noviembre.

EXXON Mobil (2008), en www.exxonmobil.cm, consultado en junio de 2009.

Gasca Neri, Rogelio (2011), Voto Razonado ante el Consejo de Administración de Pemex, Sesión Extraordinaria 835

México, 15 de noviembre, en http://www.pemex.com/files/content/votorazonado_gasca835extraordinaria.pdf, consultado en diciembre de 2011.

Gutiérrez R., Roberto (2008), “La reforma petrolera de México: ¿Dos sexenios sin política energética?”, Argumentos núm. 58, año 21, septiembre-diciembre.

(2010), "El letargo en la instrumentación de los decretos de la reforma energética", PetroQuíMex, la Revista de la Industria Petrolera, núm. 32, julio-agosto.

(2012), "La incursión de Pemex en Repsol: un experimento fallido propiciado por la reforma energética", Revista Nicolaita de Estudios Económicos Vol. VII núm. 2, julio-diciembre.

(2013), "La primera crisis financiera global del siglo XXI: orígenes, contención e implicaciones productivas y laborales", Economía: Teoría y Práctica, núm. 39, julio-diciembre.

Hansen, Royer D. (1974), La Política del Desarrollo Mexicano, 5a. edición, México, Siglo XXI Editores.

INEGI (2014), Cifras sobre el PIB y comercio exterior, en www.inegi.org.mx, consultado en febrero de 2014.

Moreno-Brid, Juan Carlos y Jaime Ros (2009), Development and Growth in the Mexican Economy. A Historical

Perspective, Nueva York, Oxford University Press (hay traducción del FCE).

NOTIMEX (2011), "Inhabilitan en Pemex a cuatro funcionarios", Excélsior, 12 de octubre.

Organización para la Cooperación y el Desarrollo Económico (OCDE) (2011), Pensions at a Glance 2011.

Retirement-Income Systems in OECD and G20 Countries, París, marzo.

Ortiz Mena, Antonio (1998), El Desarrollo Estabilizador: Reflexiones sobre una Época, México, FCE/COLMEX.

Petróleos Mexicanos (Pemex), "Indicadores petroleros", en www.pemex.com.mx cosultado en febrero de 2014. (2013), Anuario Estadístico 2013, México.

(2011), Indicadores Petroleros, septiembre, en www.pemex.com.mx, consultado en febrero de 2012.

(2011b), Contratos Integrales Exploración y Producción, en http://www.pemex.com/index.cfm?action=n ews\&sectionid=8\&catid=40\&contentid=25293 consultado el 1 de octubre de 2011 .

(2011c), Boletines de prensa, en www.pemex.com.mx, consultado en enero de 2012.

(2011d), Contratos Integrales Exploración y Producción, en http://www.pemex.com/index.cfm?action=ne

ws\&sectionid=8\&catid=40\&contentid=25293 consultado en octubre de 2011 .

(2009), Memoria de Labores 2008, México, marzo.

(2010a), Anuario Estadístico 2010, México, 2010.

(2010b), Memoria de Labores 2009, México, marzo.

(2010d), Contratos Integrales EP: Alcances y Oportunidades, diciembre.

(2004), Indicadores Petroleros, diciembre, en www.pemex.com.mx, consultado en diciembre de 2004.

Petróleos Mexicanos Internacional (PMI) (2007), "El Grupo PMI", en http://www.pmi.com.mx/Contenido/docsPortal/

Transparencia/Que_es_PMI_3.pdf consultado el 25 de octubre de 2011.

Presidencia de la República (2007), Plan Nacional de Desarrollo 2007-2012, en www.presidencia.gob.mx, consultado en junio de 2008.

Puyana, Alicia y José Romero (2009), De la Crisis de la Deuda al Estancamiento Económico, México, El Colegio de México. 
Secretaría de Hacienda y Crédito Público (SHCP) (2010a), "Versión estenográfica de la entrevista al Subsecretario de Egresos...", en www.shcp.gob.mx, 12 de noviembre, consultado en marzo de 2011.

(2010b), Criterios Generales de Política Económica para 2011, en www.shcp.gob.mx, consultado en marzo de 2011.

(2010c), Proyecto de Presupuesto de Egresos de la Federación para 2011, en www.shcp.gob.mx, consultado en marzo de 2011.

(2010d), Ley de Ingresos, en www.shcp.gob.mx, consultado en noviembre de 2011.

Secretaría de Energía (SENER) (2011), diferentes documentos a partir del diagnóstico para formular una eventual reforma energética, en www.sener.gob.mx, consultado en mayo de 2011.

Secretaría del Trabajo y Previsión Social (STPS) (2012), Estadísticas del sector, en www.stps.gob.mx, consultado en marzo de 2012.

Stiglitz, Joseph (1996), "Some lessons from the East Asian miracle", The World Bank Research Observer, Vol. 11, núm. 2, agosto. 